\title{
EVALUASI STATUS HARA BAHAN ORGANIK TERHADAP SIFAT KIMIA TANAH DI LAHAN MIRING KELAPA SAWIT
}

\author{
(Evaluation of Organic Material Nutrient Status on Soil Chemical Properties in Oil Palm \\ Leaning Land)
}

\author{
Hilwa Walida ${ }^{1}$, Fitra Syawal Harahap ${ }^{1}$, Zuriani Ritongah ${ }^{2}$, Pitri Yani ${ }^{3}$, Rendi Fitra Yana ${ }^{4}$ \\ ${ }^{1}$ Program Studi Agroteknologi, Fakultas Sains dan Teknologi Universitas Labuhanbatu, \\ Sumatera Utara, Indonesia. \\ ${ }^{2}$ Program Studi Manajemen, Fakultas Ekonomi dan Bisnis, Universitas Labuhanbatu. \\ ${ }^{3}$ Progam Studi Sumber Daya Manusia, Fakultas Ekonomi dan Bisnis, Universitas Labuhanbatu \\ ${ }^{4}$ Program Studi Komunikasi Penyiaran Islam, Fakultas Agama Islam, Universitas \\ Al Washliyah,Kabupaten Labuhanbatu, Sumatera Utara, Indonesia \\ Corresponding author : hw2191@gmail.com
}

Article Submitted : 28-08-2020

Article Accepted : 05-10-2020

\begin{abstract}
This study aims to identify the fertility variable that is an obstacle in Bilah Hulu Subdistrict, Labuhanbatu Regency by evaluating the status of soil fertility and assessing alternative management following the status of soil fertility found in the Center of the People's Palm Oil Plantation, N Satu Aek Nabara Village, Bilah Hulu District, Labuhanbatu Regency with a height of \pm 80 meters above sea level. This research is a phenomenological qualitative descriptive study with a land survey and is supported by qualitative laboratory analysis. Soil sampling is carried out in the survey area sequentially based on where the estimated nature of the soil is different from the purposive random sampling method, so the results of the soil analysis obtained are expected to reflect the true value. $60 \mathrm{~cm}$ and recording the coordinates using the Global Positioning System. Whereas soil management information is obtained by direct field observation and in-depth interviews with farmers in a snowball aiming to obtain complete information from farmers. Soil chemical properties analyzed in C-organic laboratory, CEC, Base Saturation. To determine the chemical properties of the soil with certain criteria that have been determined. Based on Technical Instructions for Evaluating Soil Fertility. Soil fertility parameters that become obstacles in the status of soil fertility in N Satu Aek Nabara Village, Bilah Hulu District, Labuhanbatu Regency are low soil organic matter content, and very low soil fertility. The direction of management of soil fertility for sloping land units in the lower, palm, and peak areas of palm oil is in the form of adding organic matter with compost and fertilizer and inorganic substances following recommendations to improve soil fertility status.
\end{abstract}

Keywords: Nutrient Status, Leaning Land, Palm Oil

\section{PENDAHULUAN}

Tanaman Kelapa Sawit (Elaeis guineensis Jacq.) merupakan salah satu tanaman perkebunan di Indonesia yang memiliki masa depan cukup cerah. Perkebunan kelapa sawit semula berkembang di daerah Sumatera Utara dan dan Kalimantan, namun sekarang telah berkembang ke berbagai daerah termasuk Sulawesi, Maluku, dan, Papua. (Nugraha et al., 2018)

Sulawesi Tenggara merupakan salah satu daerah pengembangan tanaman 
kelapa sawit, tetapi pengembangan kelapa sawit di daerah mempunyai faktor kendala terutama kesuburan tanah karena lahan pertanian di daerah ini didominasi oleh jenis tanah Ultisol yang mempunyai tingkat kesuburan rendah diperkirakan $60 \%$ dari luas areal perkebunan kelapa sawit terdapat pada tanah ultisols (Adiwiganda et al., 1994). Masalah yang dihadapi dalam pengembangan kelapa sawit di tanah ini ialah $\mathrm{pH}$ dan kandungan bahan organik rendah, miskin hara kalium $(\mathrm{K})$, kalsium (Ca), dan magnesium ( $\mathrm{Mg})$ persentase kejenuhan basa rendah, kandungan aluminium tertukar tinggi, serta mempunyai daya fiksasi tinggi (Fadhillah and Harahap, 2020).

Tanah yang diusahakan untuk bidang pertanian dan perkebuan memiliki tingkat kesuburan yang berbeda-beda. pengelolaan tanah secara tepat merupakan faktor penting dalam menentukan pertumbuhan dan hasil tanaman yang akan diusahakan (Harahap et al., 2020). Menurunnya kesuburan tanah dapat menjadi faktor utama yang mempengaruhi produktivitas tanah, sehingga penambahan unsur hara dalam tanah melalui proses pemupukan sangat penting dilakukan agar diperoleh produksi pertanian yang menguntungkan kesuburan tanah adalah proses penilaian masalah-masalah keharaan dalam tanah dan pembuatan rekomendasi pemupukan (Harahap et al., 2020).

Evaluasi status kesuburan untuk menilai dan memantau kesuburan tanah sangat penting dilakukan agar dapat mengetahui unsur hara yang menjadi kendala bagi tanaman. Penilaian evaluasi status kesuburan tanah dapat dilakukan melalui pendekatan uji tanah dimana penilaian dengan menggunakan metode ini relatif lebih akurat dan cepat (Surianto et al., 2015). Pengukuran sifat-sifat kimia tanah sebagai parameter kesuburan tanah kemudian ditetapkan dalam kriteria kesuburan tanah (Nasution et al., 2015).
Menurunnya kesuburan tanah dapat menjadi faktor utama yang mempengaruhi produktivitas tanah, sehingga penambahan unsur hara dalam tanah melalui proses pemupukan sangat penting dilakukan agar diperoleh produksi pertanian yang menguntungkan. Hasil Penelitian Harahap et al., (2019) pemberian bahan organik pada lahan miring kelapa sawit terhadap analisis kimia tanah pada kandungan bahan organik yang paling banyak jumlah ditemukan pada lahan yang berumur tua, dengan kisaran $2,61 \%$ dan didominasi lebih dari setengah komposisi tanah yang ideal Walida et al., (2019).

Bahan organik merupakan suatu sistem zat yang paling rumit dan dinamik. Secara garis besar peranan dari bahan organik adalah (1) menjaga kelembaban tanah, (2) menawarkan sifat racun dari $\mathrm{Al}$ dan $\mathrm{Fe}$, (3) penyangga hara tanaman, (4) membantu dalam meningkatkan penyediaan hara, (5) menstabilkan temperature tanah, (6) memperbaiki aktivitas organism, (7) memperbaiki struktur tanah, meningkatkan efisiensi pemupukan, dan (9) mengurangi terjadinya erosi (Harahap, 2000).Terdapat lima parameter kesuburan tanah yang digunakan dalam penelitian ini untuk menilai status kesuburan tanah, yaitu KTK; KB; C-organik; kadar P dan K total tanah sesuai petunjuk teknis evaluasi kesuburan tanah (Harahap et al., 2019).

Berdasarkan latar belakang di atas maka penelitian mengenai evaluasi status kesuburan tanah pada lahan perkebuan di Desa N Satu Aek Nabara, Kecamatan Bilah Hulu, Kabupaten Labuhanbatu sangat penting dilakukan mengingat belum adanya data terbaru status kesuburan tanah di wilayah tersebut. Data yang diperoleh dapat dimanfaatkan sebagai data dasar dan sebagai acuan dalam pengelolaan kesuburan tanah untuk budidaya tanaman pertanian agar menguntungkan dan berkelanjutan.

Penelitian ini bertujuan mengidentifikasi variabel kesuburan yang menjadi kendala di Kecamatan Bilah Hulu 
dengan melakukan evaluasi status kesuburan tanah dan mengkaji alternatif pengelolaan yang sesuai dengan status kesuburan tanah yang terdapat di sentra perkebunan kelapa sawit rakyat di Desa N Satu Aek Nabara, Kecamatan Bilah Hulu, Kabupaten Labuhanbatu

\section{METODE PENELITIAN}

Penelitian ini dilaksanakan di Sentra Perkebunan Kelapa Sawit Rakyat Desa N Satu Aek Nabara, Kecamatan Bilah Hulu, Kabupaten Labuhanbatu dengan ketinggian \pm 80 meter diatas permukaan laut. Penelitian ini merupakan penelitian deskriptif kualitatif fenomenologis dengan survai lahan dan didukung analisis laboratorium secara kualitatif. Pengambilan sampel tanah dilakukan pada areal survei secara sekuen berdasarkan tempat diperkirakan sifat tanahnya berbeda dengan metode purposive random sampling, maka hasil analisis tanah yang diperoleh diharapkan dapat mencerminkan nilai sebenarnya Pengambilan sampel tanah diambil pada lapisan atas pada kedalaman top soil $0-20$ $\mathrm{cm}, 30-60 \mathrm{~cm}$ dan dilakukan perekaman titik koordinat dengan menggunakan Global Positioning System (GPS). Sampel-sampel tanah yang telah diambil dilapangan, selanjutnya dianalisis di laboratorium (Rauf dan Harahap, 2019). Sifat-sifat kimia tanah yang dianalisis dilaboratorium C-organik ( metode Walkley and Black); KTK (metode $1 \mathrm{~N}$ NH4OAC pH 7); Kejenuhan Basa (Kation Basa/KTK*100\%); (BPT, 2009). Untuk mengetahui sifat- sifat kimia tanah dengan kriteria tertentu yang telah ditentukan. Berdasarkan Petunjuk Teknis Evaluasi Kesuburan Tanah (PPT,1995) yang disajikan pada Tabel 1.

Tabel 1. Kriteria Penilaian Sifat Kimia Tanah

\begin{tabular}{cccccc}
\hline $\begin{array}{c}\text { Sifat } \\
\text { Tanah }\end{array}$ & Sangat Rendah & Rendah & Sedang & Tinggi & $\begin{array}{c}\text { Sangat } \\
\text { Tinggi }\end{array}$ \\
\hline $\begin{array}{c}\mathrm{C}(\%) \\
\text { KTK/CEC } \\
(\mathrm{me} / 100 \mathrm{~g})\end{array}$ & $<1$ & $1-2$ & $2-3$ & $3-5$ & $>5$ \\
Kejenuhan & $<5$ & $5-16$ & $17-24$ & $25-40$ & $>40$ \\
& $<20$ & $20-40$ & $41-60$ & $61-80$ & $>80$ \\
Basa $(\%)$ & $\begin{array}{c}\text { Sangat } \\
\text { Masam }\end{array}$ & Masam & Agak Masam & Netral & Agak Alkalis \\
$\mathrm{pH}\left(\mathrm{H}_{2} \mathrm{O}\right)$ & $<4.5$ & $4.5-5.5$ & $5.6-6.5$ & $6.6-7.5$ & $7.6-8.5$ \\
\hline
\end{tabular}

Sumber : Badan Penelitian dan Pengembangan Pertanian Kementan (2012)

\section{HASIL DAN PEMBAHASAN}

Hasil Pengambilan sampel tanah di areal kelapa sawit di lahan miring pada areal bawah, lereng, puncak dengan kedalamn 0$30 \mathrm{~cm}, 30-60 \mathrm{~cm}$ dengan analisa, Bahan Organik, KTK, Kejenuhan Basa di Desa N Satu Aek Nabara, Kecamatan Bilah Hulu, Kabupaten Labuhanbatu. Hasil analisis contoh tanah di laboratorium menunjukkan bahwa Nilai pH (H2O) sedang, kandungan
Bahan organiknya sangat rendah dan sedang kandungan (Tabel 1). Dari hasil analisa Tabel 1. Analisis kesuburan tanah di lahan miring pada pertanaman kelapa sawit menunjukkan hasil analisis kejenuhan basa sangat rendah $1,12 \%$ dapat dikatakan tingkat kesuburan tanah di lokasi percobaan tergolong sangat rendah, yang sejalan dengan nilai $\mathrm{pH}$ tanahnya yang tergolong netral $(6,5)$. Kadar C-organik yang sangat rendah $(0,36 \%)$ (Tabel 1$)$. Tabel 1. 
mengindikasikan tanah ini membutuhkan tambahan bahan organik sehingga dapat mendukung pertumbuhan dan perkembangan tanaman kelapa sawit yang hidup diatasnya.

Rendahnya status kesuburan tanah pada lokasi penelitian disebabkan karena adanya faktor pembatas, yaitu rendahnya kandungan C- organik tanah dan Kejenuhan Basa. Kandungan C-organik (bahan organik) tanah sangat berpengaruh terhadap kemampuan tanah dalam mempertahankan kesuburan dan produktivitas tanah melalui aktivitas mikroorganisme tanah. Hal ini sesuai dengan pendapat Tolaka, (2013) Penambahan bahan organik mutlak harus diberikan karena bahan organik tanah sangat berperan penting untuk menciptakan kesuburan tanah. Peran bahan organik bagi tanah merupakan pembentuk granulasi dalam tanah dan sangat penting dalam pembentukan agregat tanah yang stabil (Rauf dan Harahap, 2020).

Penyebaran nilai C-organik pada ke tiga unit lahan tergolong beragam yaitu rendah sampai sedang dengan kisaran 1.08 $\%$ sampai $3.04 \%$. Keadaan ini disebabkan karena tanah pada lokasi penelitian terlalu sering diolah tanpa adanya pengembalian bahan organik sisa-sisa panen, seperti pelepah panen atau penggunaan pupuk organic.(Syawal dan Rauf, 2017). Selain itu petani enggan menambahkan pupuk organik dalam pengelolaan tanahnya sehingga keadaan ini menyebabkan kehilangan bahan organik melalui panen semakin tinggi. Kandungan C-organik tanah selain dapat menentukan besarnya nilai KTK tanah juga sangat menentukan penambahan unsur hara yang dikandungnya seperti $\mathrm{N}, \mathrm{P}, \mathrm{K}, \mathrm{Ca}, \mathrm{Mg}$, S serta unsur mikro (Luta et al., 2020).

Tabel 2. Analisis kesuburan tanah di areal kelapa sawit di lahan miring

\begin{tabular}{ccccccc}
\hline $\begin{array}{c}\text { Tahun } \\
\text { Tanam }\end{array}$ & Areal & $\begin{array}{c}\text { Kedalaman } \\
(\mathrm{cm})\end{array}$ & $\begin{array}{c}\text { Bahan } \\
\text { Organik }\end{array}$ & $\begin{array}{c}\text { KTK } \\
(\mathrm{me} / 100 \mathrm{~g})\end{array}$ & $\begin{array}{c}\text { Kejenuhan } \\
\text { Basa }(\%)\end{array}$ & pH Tanah \\
\hline $\mathrm{V}$ & Bawah & $0-30$ & $2.35(\mathrm{~S})$ & $30.84(\mathrm{~T})$ & $5.94(\mathrm{SR})$ & $5.74(\mathrm{~S})$ \\
& & $30-60$ & $2.18(\mathrm{~S})$ & $28.12(\mathrm{~T})$ & $4.36(\mathrm{SR})$ & $5.66(\mathrm{~S})$ \\
& Lereng & $0-30$ & $2.32(\mathrm{~S})$ & $35.45(\mathrm{~T})$ & $1.16(\mathrm{SR})$ & $5.60(\mathrm{~S})$ \\
& & $30-60$ & $1.08(\mathrm{R})$ & $30.42(\mathrm{~T})$ & $1.46(\mathrm{SR})$ & $5.70(\mathrm{~S})$ \\
& Puncak & $0-30$ & $2.30(\mathrm{~S})$ & $30.29(\mathrm{~T})$ & $1.16(\mathrm{SR})$ & $6.02(\mathrm{~S})$ \\
& & $30-60$ & $1.94(\mathrm{R})$ & $31.14(\mathrm{~T})$ & $1.12(\mathrm{SR})$ & $6.08(\mathrm{~S})$ \\
\hline \multirow{3}{*}{ XV } & \multirow{3}{*}{ Bawah } & $0-30$ & $2.35(\mathrm{~S})$ & $34.49(\mathrm{~T})$ & $10.80(\mathrm{SR})$ & $6.02(\mathrm{~S})$ \\
& & $30-60$ & $2.58(\mathrm{~S})$ & $33.91(\mathrm{~T})$ & $7.07(\mathrm{SR})$ & $5.58(\mathrm{R})$ \\
& Lereng & $0-30$ & $3.04(\mathrm{~S})$ & $30.98(\mathrm{~T})$ & $5.41(\mathrm{SR})$ & $5.86(\mathrm{~S})$ \\
& & $30-60$ & $2.36(\mathrm{~S})$ & $33.37(\mathrm{~T})$ & $5.24(\mathrm{SR})$ & $5.86(\mathrm{~S})$ \\
& Puncak & $0-30$ & $2.68(\mathrm{~S})$ & $30.51(\mathrm{~T})$ & $5.09(\mathrm{SR})$ & $5.99(\mathrm{~S})$ \\
& & $30-60$ & $2.64(\mathrm{~S})$ & $32.82(\mathrm{~T})$ & $3.93(\mathrm{SR})$ & $6.07(\mathrm{~S})$ \\
\hline
\end{tabular}

Keterangan : AM: Agak Masam, SR: Sangat Rendah, R:Rendah, T:Tinggi, ST: Sangat Tinggi

Hal ini didukung oleh Sevindrajuta, (2012) Pemberian bahan organik tidak hanya menambah unsur hara bagi tanaman, tetapi juga dapat menciptakan kondisi yang sesuai untuk tanaman dan memperbaiki aerasi, mempermudah penetrasi akar, memperbaiki kapasitas menahan air, meningkatkan $\mathrm{pH}$ tanah, KTK, dan serapan hara Bahan organik tanah sangat menentukan interaksi antara komponen abiotik dan biotik dalam 
ekosistem tanah. Harahap et al., (2020), dalam penelitiannya menyatakan bahwa kandungan bahan organik dalam bentuk Corganik di tanah harus dipertahankan tidak kurang dari 2 persen. Keadaan ini diperlukan agar kandungan bahan organik dalam tanah tidak menurun dengan waktu akibat proses dekomposisi mineralisasi. Penambahan bahan organik pada saat pengelolaan tanah mutlak diperlukan setiap tahun.

Kapasitas Tukar Kation pada ke tiga unit lahan tergolong tinggi dengan kisaran 35,45 sampai dengan 30,51 Kapasitas Tukar Kation (KTK) tanah merupakan kemampuan koloid tanah menjerap dan mempertukarkan kation (Tan, 1991). Tingginya nilai KTK tanah pada ketiga unit lahan disebabkan karena kedua jenis tanah yang dijumpai pada daerah penelitian termasuk ke dalam tanah muda dan baru berkembang dan belum banyak mengalami proses pencucian. Hal ini sesuai dengan pendapat Surya et al.,(2019), Keadaan ini didukung juga oleh data $\mathrm{pH}$ yang berkisar antara 6,9-7 yang tergolong netral Besarnya KTK sangat ditentukan oleh pH tanah, tekstur tanah atau kadar liat, jenis mineral liat, kandungan bahan organik dan pemupukan.

Nilai kejenuhan basa pada ke tiga unit lahan tergolong sangat rendah yaitu berkisar 10,80 sampai $1,12 \%$. Sangat rendahnya nilai kejenuhan basa pada areal unit lahan menunjukkan topografi pada lokasi penelitian tergolong datar sehingga kecil kemungkinan terjadinya erosi dan keadaann ini memberikan pengaruh sangat kecil terhadap hilangnya basa-basa. Kejenuhan Basa (KB) secara relatif ditentukan oleh jumlah kation basa dan reaksi tanah $(\mathrm{pH})$. nilai kejenuhan basa, hal ini juga didukung oleh tingginya kadar kation K-total tanah. Kation K merupakan kation basa yang sangat menentukan nilai $\mathrm{KB}$ tanah. Nilai $\mathrm{pH}$ tanah yang terdapat pada ketiga unit lahan menunjukkan selain kation $\mathrm{K}$ terdapat kation-kation basa yang lain seperti Ca, Mg, dan Na (Surya et al., 2019).

\section{KESIMPULAN}

Berdasarkan hasil penelitian dan pembahasan maka dapat disimpulkan bahwa:

1. Parameter kesuburan tanah yang menjadi kendala dalam status kesuburan tanah di Desa N Satu Aek Nabara, Kecamatan Bilah Hulu, Kabupaten Labuhanbatu ialah kandungan Bahan Organik tanah rendah dan Kejunah Basah tanah yang sangat rendah.

2. Arahan pengelolaan kesuburan tanah untuk unit lahan miring di areal kelapa sawait bagian bawah, lerang, puncak berupa tindakan penambahan bahan organik dengan kompos dan pupuk dan anorganik sesuai dengan rekomendasi untuk meningkatkan status kesuburan tanahnya.

\section{UCAPAN TERIMA KASIH}

Penulis mengucapkan terima kasih kepada Rektor Universitas Labuhanbatu yang bersedia memberikan dana hibah internal dan ijin melakuan penelitian dilapangan serta keikhlasan waktu dan ide kepada penulis demi kesempurnaan penulisan karya ilmiah ini.

\section{DAFTAR PUSTAKA}

Adiwiganda, R., Lubis, A.U. and Purba, P., 1994. Karakteristik tanah pada beberapa tingkat famili di areal kelapa sawit di Indonesia. Berita Pusat Penelitian Kelapa Sawit,2(3), pp.174-188.

Badan Penelitian dan Pengembangan Pertanian Kementerian Pertanian. 2012. Petunjuk Teknis Analisis Kimia Tanah, Tanaman, Air dan Pupuk. Edisi 2. Bogor. 204 hal

Balai Penelitian Tanah - Badan Penelitian dan Pengembangan Pertanian. 2009. Perangkat Uji Tanah Kering (PUTK). Departemen Pertanian. 
Fadhillah, W. and Harahap, F.S., 2020. Pengaruh Pemberian Solid (Tandan Kosong Kelapa Sawit) Dan Arang Sekam Padi Terhadap Produksi Tanaman Tomat. Jurnal Tanah dan Sumberdaya Lahan, 7(2), pp.299-304.

Harahap, E.M., 2000. Pembuatan Asam Organik untuk Pupuk. Lokakarya Pengembangan Budidaya Kewirausahaan Melalui Bahan Ajar. Jurusan Ilmu Tanah FP-USU. Medan.

Harahap, F.S., Arman, I., Wicaksono, M., Mico, W.T., Rauf, A. and Walida, H., 2019. Pemberian Bahan Organik Pada Lahan Miring Kelapa Sawit Terhadap Analisis Kimia Tanah. Agrica Ekstensia, 13(2), pp.47-54.

Harahap, F.S., Harahap, D.E. and Harahap, P., 2020. Land Characteristics And Land Evaluation For Development On Other Use Area Rice Fertilizer Plants In District Salak Regency Pakpak Bharat. Ziraa'ah Majalah Ilmiah Pertanian, 45(2), pp.195-204.

Harahap, F.S., Sitompul, R., Rauf, A., Harahap, D.E. and Walida, H., 2019, May. Land suitability evaluation for oil palm plantations (Elaeis guenensis jacq) on Sitellu Tali Urang Julu, Pakpak Bharat District. In IOP Conference Series: Earth and Environmental Science (Vol. 260, No. 1, p. 012116). IOP Publishing.

Harahap, F.S., Walida, H., Dalimunthe, B.A., Rauf, A., Sidabuke, S.H. and Hasibuan, R., 2020. The Use of Municipal Solid Waste Composition in Degradated Waste Soil Effectiveness in Aras Kabu Village, Beringin Subdistrict, Deli Serdang District. Agrinula, 3(1), pp.19-27.
Harahap, F.S., Walida, H., Rahmaniah, R., Rauf, A., Hasibuan, R. and Nasution, A.P., Pengaruh Aplikasi Tandan Kosong Kelapa Sawit dan Arang Sekam Padi terhadap beberapa Sifat Kimia Tanah pada Tomat. Agrotechnology Research Journal, 4(1), pp.1-5.

Luta, D.A., Siregar, M., Sabrina, T. and Harahap, F.S., 2020. Peran Aplikasi Pembenah Tanah Terhadap Sifat Kimia Tanah Pada Tanaman Bawang Merah. Jurnal Tanah dan Sumberdaya Lahan, 7(1), pp.121-125.

Nasution, S.H., Hanum, C. and Ginting, J., 2014. Pertumbuhan bibit kelapa sawit (Elaeis Guineensis Jacq.) pada berbagai perbandingan media tanam solid decanter dan tandan kosong kelapa Sawit pada sistem single stage. Jurnal Agroekoteknologi Universitas Sumatera Utara,2(2), p.98564.

Nugraha, M.A.S., Gunawan, S. and Santi, I.S., 2018. Pengaruh Kualitas Panen Terhadap Losses Diperkebunan Kelapa Sawit Di Pt Wanasawit Subur Sumber Lestari 2. Jurnal Agromast, 3(1).

Rauf, A. and Harahap, F.S., 2019, November. Evaluation of peat soil properties for oil palm plantation in nine years of plant at Kubu Raya District, West Kalimantan, Indonesia. In IOP Conference Series: Earth and Environmental Science (Vol. 374, No. 1, p. 012040). IOP Publishing.

Rauf, A. dan Harahap, F.S. 2019. Optimalisasi Lahan Pertanian Menggunakan Agen Biomassa. USU Press. Medan. ISBN : 978-602-465146-6. 
Sevindrajuta. 2012. Efek Pemberian Beberapa Takaran Pupuk Kandang Sapi Terhadap Sifat Kimia Inceptisol dan Pertumbuhan Tanaman Bayam Cabut (Amarathus tricolor, L). Universitas Muhamadiyah. Sumatra Barat.

Sudaryono. 2009. Tingkat Kesuburan tanah Ultisol pada Lahan Pertambangan Batu Bara Sangatta Kaltim. Jurnal Tek ling. 10( 3,): 337-346.

Supriyadi, S., 2008. Kandungan bahan organik sebagai dasar pengelolaan tanah di lahan kering Madura. Jurnal Embryo, 5(2), pp.176-183.

Surianto, S., Rauf, A., Sabrina, T. and Sutarta, E.S., 2015. Karakteristik Tanah Dan Perbandingan Produksi Kelapa Sawit (Elaeis Guineensis Jacq.) Dengan Metode Tanam Lubang Besar Dan Parit Drainase 2: 1 Pada Lahan Spodosol Di Kabupaten Barito Timur Propinsi Kalimantan TengahIndonesia. Pertanian Tropik, 2(2), p.157007.

Surya, E., Hanum, H., Hanum, C. and Harahap, F.S., 2019. Pengaruh Pemberian Kompos Bunker Diperkaya Dengan Limbah Cair Pabrik Kelapa Sawit Pada Pertumbuhan Bibit Kelapa Sawit Di Bibitan Utama. Jurnal Tanah dan Sumberdaya Lahan, 6(2), pp.12811289.
Surya, E., Hanum, H., Hanum, C., Rauf, A., Hidayat, B. and Harahap, F.S., 2019. Effects of Composting on Growth and Uptake of Plant Nutrients and Soil Chemical Properties After Composting with Various Comparison of POME. International Journal of Environment, Agriculture and Biotechnology, 5(6).

Syawal, F. and Rauf, A., 2017. Upaya Rehabilitasi Tanah Sawah Terdegradasi Dengan Menggunakan Kompos Sampah Kota Di Desa Serdang Kecamatan Beringin Kabupaten Deli Serdang. Jurnal Pertanian Tropik, 4(3), pp.183-189.

Tan, K.H. and Goenadi, I.D.H., 1991. Dasar-dasar kimia tanah. Gadjah Mada University Press.

Tolaka, W., Wardah, W. and Rahmawati, R., 2013. Sifat Fisik Tanah Pada Hutan Primer, Agroforestri dan Kebun Kakao di SUBDAS Wera Saluopa Desa Leboni Kecamatan Pamona Puselemba Kabupaten Poso. Jurnal Warta Rimba, 1(1).

Walida, H., Harahap, F.S., Hasibuan, M. and Yanti, F.F., 2019. Isolasi dan Identifikasi Bakteri Penghasil IAA dan Pelarut Fosfat dari Rhizosfer Tanaman Kelapa Sawit. BIOLINK (Jurnal Biologi Lingkungan Industri Kesehatan), 6(1), pp.1-7. 